\title{
Admission and Acute Complication Rate for Outpatient Lumbar Microdiscectomy
}

\author{
Aria Fallah, Eric M. Massicotte, Michael G. Fehlings, Stephen J. Lewis, \\ Yoga Raja Rampersaud, Shanil Ebrahim, Mark Bernstein
}

\begin{abstract}
Objective: Specialization is generally independently associated with improved outcomes for most types of surgery. This is the first study comparing the immediate success of outpatient lumbar microdiscectomy with respect to acute complication and conversion to inpatient rate. Long term pain relief is not examined in this study. Methods: Two separate prospective databases (one belonging to a neurosurgeon and brain tumor specialist, not specializing in spine (NS) and one belonging to four spine surgeons (SS)) were retrospectively reviewed. All acute complications as well as admission data of patients scheduled for outpatient lumbar microdiscectomy were extracted. Results: In total, 269 patients were in the NS group and 137 patients were in the SS group. The NS group averaged 24 cases per year while the SS group averaged 50 cases per year. Chi-square tests revealed no difference in acute complication rate $[\mathrm{NS}(6.7 \%), \mathrm{SS}(7.3 \%)](\mathrm{p}>0.5)$ and admission rate $[\mathrm{NS}(4.1 \%), \mathrm{SS}(5.8 \%)](\mathrm{p}=0.4)$ while the $\mathrm{SS}$ group had a significantly higher proportion of patients undergoing repeat microdiscectomy [NS(4.1\%), SS(37.2\%)] (p<0.0001). Excluding revision operations, there was no statistically significant difference in acute complication $[\mathrm{NS}(5.4 \%), \mathrm{SS}(1.2 \%)](\mathrm{p}=0.09)$ and conversion to inpatient $[\mathrm{NS}(4.3 \%), \mathrm{SS}(4.6 \%)](\mathrm{p}>0.5)$ rate. The combined acute complication and conversion to inpatient rate was $6.9 \%$ and $4.7 \%$ respectively. Conclusion: Based on this limited study, outpatient lumbar microdiscectomy can be apparently performed safely with similar immediate complication rates by both non-spine specialized neurosurgeons and spine surgeons, even though the trend favored the latter group for both outcome measures.
\end{abstract}

RÉSUMÉ: Hospitalisation et taux de complications aiguës chez les patients qui subissent une microdiscectomie lombaire en externe. Objectif : Spécialisation est généralement associée de façon indépendante à de meilleurs résultats dans la plupart des types de chirurgies. Il s'agit de la première étude comparant le taux de complications aiguës et l'hospitalisation pour évaluer le succès immédiat de la microdiscectomie lombaire en externe. Le soulagement de la douleur à long terme n'a pas été examiné dans cette étude. Méthodes : Nous avons révisé rétrospectivement deux bases de données prospectives (celle d'un neurochirurgien, spécialiste du traitement de tumeurs cérébrales, mais non pas de la colonne vertébrale (NS) et celle de 4 chirurgiens spécialistes de la colonne vertébrale (SS)). Toutes les données concernant les complications aiguës et les hospitalisations des patients inscrits pour une microdiscectomie lombaire en externe ont été extraites. Résultats : En tout, 269 patients appartenaient au groupe NS et 137 patients au groupe SS. Le groupe NS comptait en moyenne environ 24 cas par année alors que le groupe SS en comptait 50 par année. Les tests du chi-carré n’ont montré aucune différence quant au taux de complications aiguës (NS 6,7\%; SS 7,3\%; p >0,5) et au taux d'hospitalisation (NS 4,1\%; SS 5,8\%; p = 0,4) et le groupe SS avait une proportion significativement plus élevée de patients qui subissaient une nouvelle microdiscectomie (NS 4,1\%; SS 37,2\%; p < $0,0001)$. Après exclusion des reprises chirurgicales, il n'existait pas de différence significative au point de vue statistique quant aux complications aiguës (NS 5,4\%; SS 1,2\%; p = 0,09) et au taux d'hospitalisation (NS 4,3\%; SS 4,6\%; p > 0,5). Le taux combiné de complications aiguës et d'hospitalisation était de $6,9 \%$ et de $4,7 \%$ respectivement. Conclusion : La microdiscectomie lombaire effectuée en externe peut, selon notre étude dont la portée est limitée, être effectuée sans danger et comporte des taux de complications immédiates similaires, que ce soit fait par un neurochirurgien non spécialisé en chirurgie de la colonne vertébrale ou par un chirurgien spécialisé en chirurgie de la colonne vertébrale, bien qu'il y ait une tendance favorisant ce dernier groupe dans les deux mesures d'évaluation utilisées dans notre étude.

Can. J. Neurol. Sci. 2010; 37: 49-53

Specialization is generally independently associated with improved outcomes for all types of surgery. ${ }^{1-2}$ This is primarily attributed to specialized surgeons being more likely to perform higher volumes of select procedures. ${ }^{1}$

Degenerative disc disease of the lumbar spine is a prevalent and costly ailment that often requires surgical intervention. ${ }^{3} \mathrm{~A}$ significant number of patients have further reoperations [14\%] or develop failed back syndrome [8-25\%] which is failure to improve satisfactorily following surgery.4-6 Unsuccessful operations are largely attributed to incomplete discectomy, nerve root fibrosis, recurrent herniation, or underlying spinal instability. ${ }^{7}$

\footnotetext{
From the Division of Neurosurgery (AF, EMM, MGF, MB), Division of Orthopedic Surgery (SJL, YRR), Institute of Medical Sciences (SE), University of Toronto, Toronto, Ontario, Canada.

Received April 30, 2009. Final Revisions Submitted July 8, 2009. Correspondence to: Mark Bernstein, Toronto Western Hospital, 399 Bathurst Street, Toronto, Ontario, M5T 2S8, Canada.
} 
The increasing amount of outpatient surgery is largely attributed to improved anaesthetic techniques and agents, patient convenience and advances in surgical technique. ${ }^{8}$ Specifically, outpatient microdiscectomy has been demonstrated to be a safe procedure that also allows significant financial savings to the health care system., 3 This is the first study comparing the immediate success of outpatient lumbar microdiscectomy vis-àvis acute complication and conversion to inpatient for spine surgeons and a non-spine surgeon (brain tumor specialist).

\section{MethodS}

Two separate prospective databases were reviewed to include patients for this study. Patient data of a non-spine neurosurgeon from February 25, 1997 to June 24, 2008 and patient data of four spine surgeons from August 4, 2005 to May 29, 2008, both from the same institution, were examined. The non-spine neurosurgeon's database is updated personally by the surgeon after each operation and only includes outpatient microdiscectomies. The spine surgeons' database includes comprehensive and standardized forms completed at the time of surgery by the staff surgeon or his designate for each spine case. The form includes information about the indications, presentation, surgery and complications. There was a total of 1835 spine cases in this database.

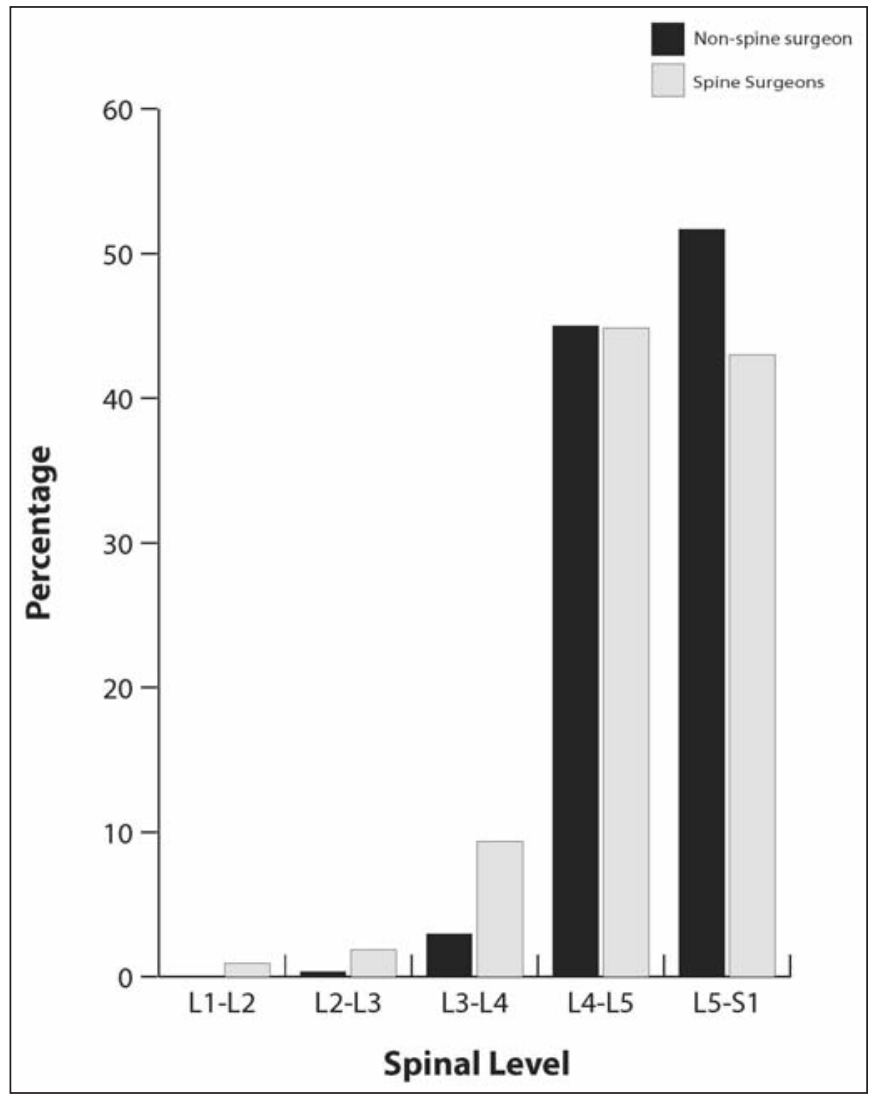

Figure 1: Distribution of cases by spinal level.
The patients in the non-spine neurosurgeon (NS) group were operated on by a single neurosurgeon (MB) who focuses on surgical neuro-oncology but also does outpatient lumbar microdiscectomy. He does not have additional fellowship training in spine and devotes approximately $10 \%$ of his practice to spinal operations. The patients comprising the spine surgeon (SS) group came from the practice of four fellowship trained spine surgeons. These four spine surgeons included two neurosurgeons (MGF and EMM) and two orthopedic surgeons (SJL and YRR) who almost exclusively restrict their practice to spinal surgery. The institution where this study was conducted was an academic centre, therefore fellows and/or residents are involved with all cases and no surgeon operates independently. All surgeries were performed according to the graduated responsibility model of teaching. The NS was routinely present for the surgery and was scrubbed for the final stages of decompression. The SS were routinely scrubbed for the operation. The NS and two of the SS performed their microdiscectomies via the conventional method while two SS (EMM and YRR) routinely used a tubular-assisted method. All patients included in the study were operated at the same institution, over the age of 18 years and scheduled to receive an elective outpatient lumbar microdiscectomy. The data extracted from the database included age, gender, date of surgery, site of

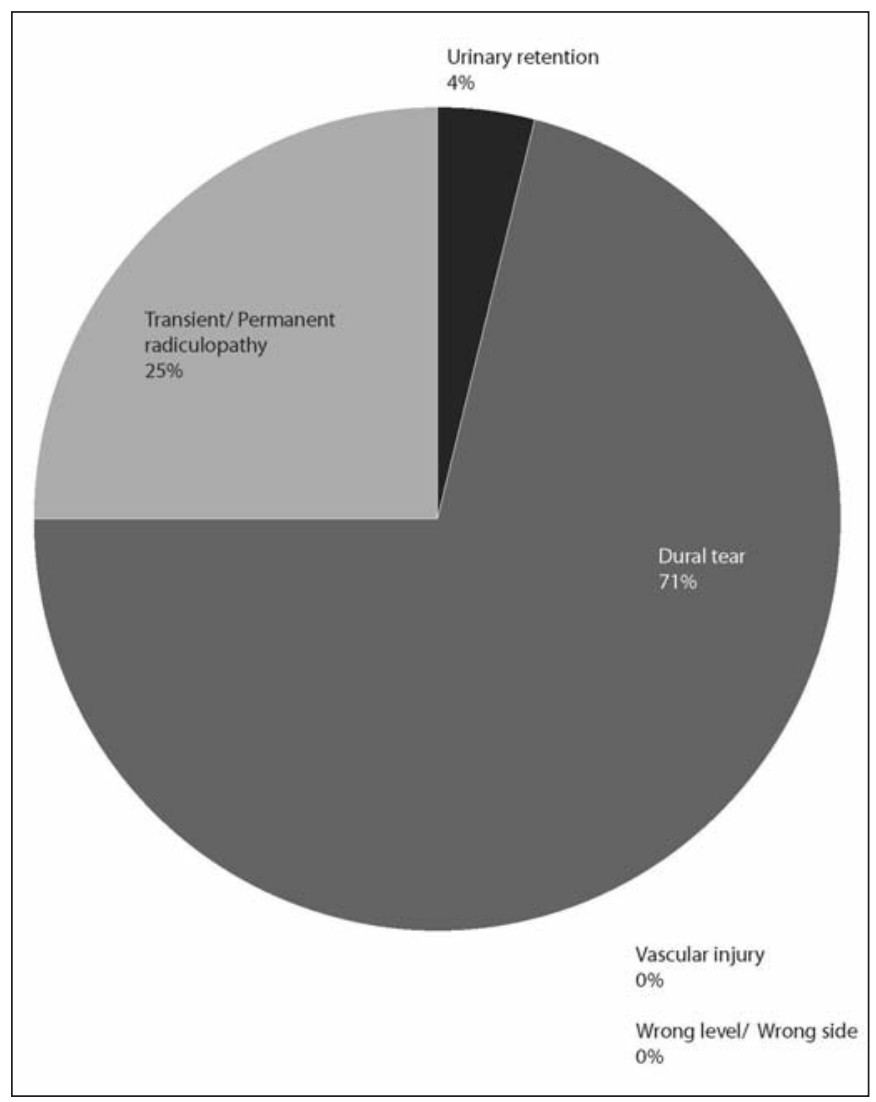

Figure 2: Distribution of acute complications. 
Table 1: Summary of data

\begin{tabular}{c|c|c|c|c|c|c|c}
\hline Group & Range of dates & $\begin{array}{c}\text { Age } \\
(\mathrm{yrs})\end{array}$ & $\begin{array}{c}\text { Total } \\
\text { cases }\end{array}$ & $\begin{array}{c}\mathrm{n}(\%) \\
\text { female }\end{array}$ & $\begin{array}{c}\text { Redo } \\
\mathrm{n}(\%)\end{array}$ & $\begin{array}{c}\text { Acute complication } \\
\mathrm{n}(\%)\end{array}$ & $\begin{array}{c}\text { Conversion to } \\
\text { inpatient } \mathrm{n}(\%)\end{array}$ \\
\hline NS & $\begin{array}{c}25 / 02 / 1997- \\
24 / 06 / 2008\end{array}$ & 44 & 269 & $126(47)$ & $11(4.1)$ & $18(6.7)$ & $11(4.1)$ \\
& $\begin{array}{c}04 / 08 / 2005- \\
29 / 05 / 2008\end{array}$ & 45 & 137 & $57(42)$ & $51(37.2)$ & $10(7.3)$ & $8(5.8)$ \\
\hline
\end{tabular}

surgery, first vs. second surgery, acute complications, and conversion to inpatient. Long term pain relief was not examined in this study. We defined acute complications as dural tear, transient/permanent radiculopathy, urinary retention, vascular injury, wrong level and wrong side surgery. Admissions were defined as any patient who required admission on the day of surgery and therefore was not directly discharged from the 'Day Surgery Unit'. Appropriate statistical analyses were performed with recognition that the sample size may be underpowered. This study was approved by the 'Research Ethics Board' of the 'University Health Network'.

\section{RESUlTS}

The data for both databases were complete. Three duplicate entries were discarded in the SS database while the NS database had no duplicate entries. This review resulted in inclusion of 406 patients: 269 patients in the NS group and 137 patients in the SS group. The two groups were comparable in terms of mean age (44 vs. 45 years of age) and gender (47 vs. $42 \%$ female), respectively as well as site of surgery (Figure 1 ). The average number of cases per year for the NS group was 24 while the SS group was 50 .

Acute complications comprised of dural tear [NS(10), $\mathrm{SS}(10)]$, urinary retention [NS(1), $\mathrm{SS}(0)]$ and transient/ permanent radiculopathy $[\mathrm{NS}(7), \mathrm{SS}(0)]$ for a combined rate of $6.9 \%$. Dural tears and radiculopathy alone accounted for over $95 \%$ of complications (Figure 2). With revision operations excluded, complications of dural tears [NS(7), SS(1)], urinary retention $[\mathrm{NS}(1), \mathrm{SS}(0)]$ and transient/permanent radiculopathy [NS(6), SS(0)] combined to $4.4 \%$. There was no difference in acute complication $\left[\chi^{2}=0.05(\mathrm{p}>0.5)\right]$ and admission $[\chi 2=0.62$ $(\mathrm{p}=0.4)$ ] rates between the SS and NS groups (Table 1, Figure 3). Only considering revision operations resulted in no difference between acute complication $\left[\chi^{2}=1.88(\mathrm{p}=0.2)\right]$ and admission rates (Table 3 ). Admissions were not necessarily secondary to a surgical complication and were often the result of an anesthetic complication and on one occasion, due to social reasons. Furthermore, the SS group had a significantly higher number of patients undergoing a revision operation than the NS group $\left[\chi^{2}=\right.$ $76.84(\mathrm{p}<0.0001)]$. With the exclusion of revision operations, there was no statistically significant difference with respect to acute complication $\left[\chi^{2}=2.80(\mathrm{p}=0.09)\right]$ and conversion to inpatient $\left[\chi^{2}=0.02(\mathrm{p}>0.5)\right]$ rate (Table 2, Figure 3$)$.

We reviewed the medical records of the 19 admitted patients to retrieve the cause of admission: dural tear $(3 ; 16 \%)$, airway compromise $(3 ; 16 \%)$, urinary retention $(2 ; 11 \%)$, hemibody numbness $(1 ; 5 \%)$, pain management $(2 ; 11 \%)$, vomiting $(2 ; 11 \%)$, patient's request $(1 ; 5 \%)$ and undocumented $(5 ; 26 \%)$.

\section{DISCUSSION}

The safety and patient satisfaction of outpatient microdiscectomy has already been established., ${ }^{2,10}$ The acute complication rate of microdiscectomy from large series is from $1.5 \%$ to $15.8 \% .^{7}$ Our results for both groups fall into this range. The large discrepancy of repeat operations is expected as patients with recurrent intravertebral disc herniation are more likely to be referred to a fellowship-trained surgeon focusing mainly on spine as opposed to a neurosurgeon who is not fellowship-trained in spine and not mainly focusing on complex spine surgery. The incidence of intraoperative complications, and more specifically
Table 2: Revision operations excluded

\begin{tabular}{c|c|c|c}
\hline Group & $\begin{array}{c}\text { Total } \\
\text { cases }\end{array}$ & $\begin{array}{c}\text { Acute complication } \\
\mathrm{n}(\%)\end{array}$ & $\begin{array}{c}\text { Conversion to } \\
\text { inpatient } \mathrm{n}(\%)\end{array}$ \\
\hline NS & 258 & $14(5.4)$ & $11(4.3)$ \\
\hline SS & 86 & $1(1.2)$ & $4(4.6)$ \\
\hline
\end{tabular}

Table 3: Revision operations

\begin{tabular}{c|c|c|c}
\hline Group & $\begin{array}{c}\text { Total } \\
\text { cases }\end{array}$ & $\begin{array}{c}\text { Acute complication } \\
\mathrm{n}(\%)\end{array}$ & $\begin{array}{c}\text { Conversion to } \\
\text { inpatient n(\%) }\end{array}$ \\
\hline NS & 11 & $4(36.4)$ & $0(0.0)$ \\
\hline SS & 51 & $9(17.6)$ & $4(7.8)$ \\
\hline
\end{tabular}




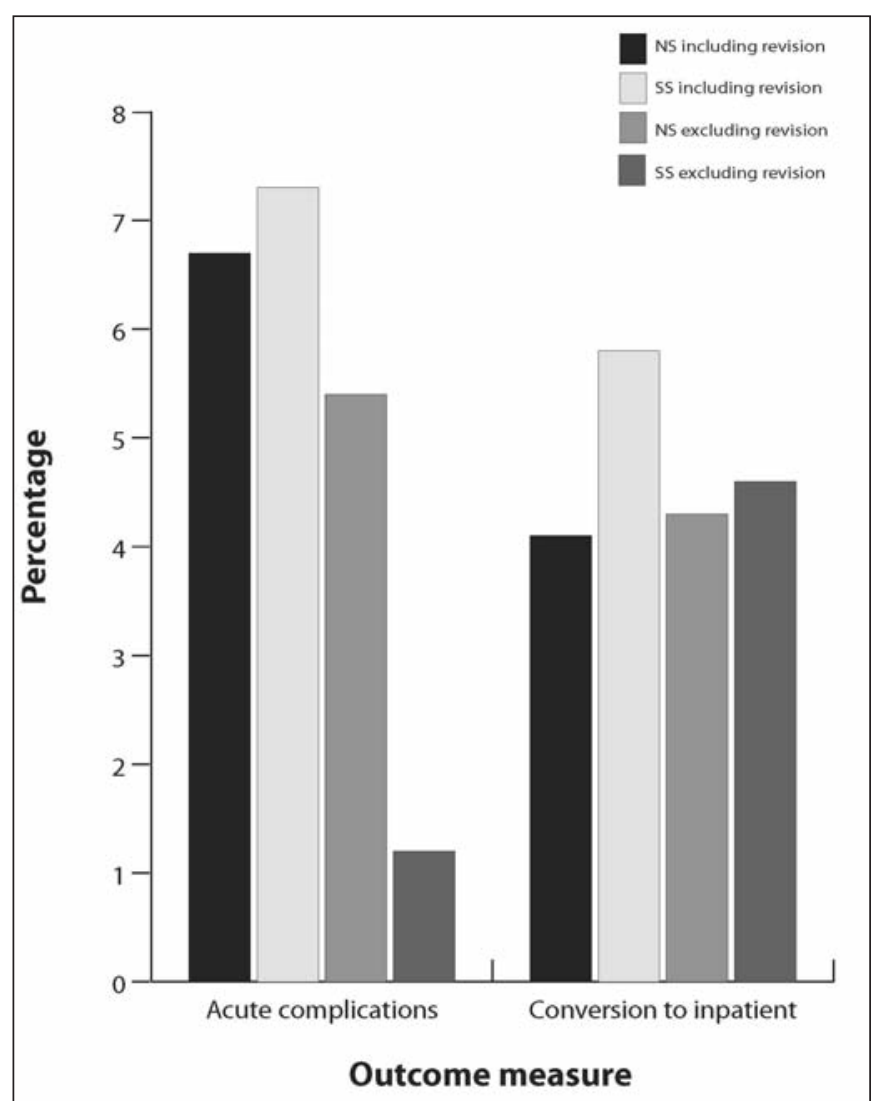

Figure 3: Acute complication and conversion to inpatient rate with and without revision operations comparing spine surgeons to a non-spine surgeon.

perforation of the dura, is significantly greater in reoperations when compared to primary herniated lumbar disc surgery. ${ }^{11}$ Subgroup analysis excluding revision operations did not result in a statistically significant difference in acute complication rate likely as a result of the low sample size in the SS group. Its clinical significance however, cannot be excluded.

Excluding the large proportion of revision surgery in the SS group did not result in a significant difference in admission rates between the two groups. Again, this might be due to a low sample size. A key factor influencing early discharge of patients undergoing outpatient microdiscectomy is anesthetic complications such as pain, nausea, vomiting and ocular complications. ${ }^{12-14}$ Occasionally, patients are admitted due to social reasons such as lack of caregiver at home. ${ }^{8}$ Admission rates can also be largely influenced by the individual surgeon's comfort level. A large study performed by a single orthopedic spine surgeon demonstrated an admission rate of $1.7 \% .^{13}$ This is consistent with the $1.2 \%$ admission rate amongst the spine surgeons in this study. The most valuable measure of admission rates for the purpose of this study would be to isolate those that were secondary to a surgical complication. Our results demonstrate that approximately half of the admissions are directly related to a surgical complication.
Wiese et al's study found a significant difference of intra- and peri- operative complications that were related to surgeon's experience. $^{7}$ This has been demonstrated amongst various specialties and procedures. ${ }^{1}$ Our study findings are not contradictory as information regarding operative experience of individual surgeons was not analyzed. Although more valuable information can be obtained when comparing volume-dependent complication and admission rates, volume stratification poses its own challenges as it is largely opinion based and difficult to track unless done in a prospective fashion.

\section{Limitations of this study}

There are a few important discordances in the two data sets. First, there are an uneven number of patients in the two groups of our study. The spine surgeons' prospective database was only started in 2005 and therefore has lower numbers. The non-spine surgeon's prospective database was created when he began performing outpatient lumbar microdiscectomy in 1997 and therefore it represents the larger proportion of this data. Second, there is only one surgeon comprising the non-spine surgeon group. Other non-spine surgeons at our institution, who have done a significant although much smaller number of outpatient lumbar microdiscectomy, did not keep prospective databases so their data were not readily retrievable. Third, the data represents different epochs (1997-2008 vs. 2005-2008) further adding to the discordance of the two study arms.

An important limitation is the quality of our data. It may contain inaccuracies just by the nature of its collection. There is no way to know if every complication is accurately captured. However, it is unlikely that conversions to inpatient were missed. Further limitations of this study include its retrospective methodology (although the data were collected prospectively, they were analyzed retrospectively), the biases associated with referral patterns to specialists, and the involvement of surgical trainees. The involvement of surgical trainees according to the graduated responsibility teaching model has not been associated with negative outcomes for aneurysm surgery and with proper staff supervision, it is likely that the same would obtain for a procedure like microdiscectomy. ${ }^{15}$

Other data points that are relevant to this topic but were outside the scope of our study were post-operative pain recorded by a visual analog scale, the anesthetic record and length of stay in the recovery unit. These factors as well as the lower threshold for admission amongst surgeons for revision surgery might further support these findings.

Although we recognize that comparisons of non-randomized groups are fraught with problems, we hope this study provides useful data as it is a relatively large series. ${ }^{16}$ In retrospect, lumbar microdiscectomy may not be the right procedure to compare non-spine to spine surgeons in their ability to perform spine surgery. These results might have been expected as many would not consider lumbar microdiscectomy to be a highly specialized spine procedure, but more a "bread and butter" operation performed routinely by many neurosurgeons and orthopedic surgeons. However, the question we tried to address is still an interesting one, likely requiring a different study design to answer. The question was: "Who does a procedure better - a non specialist (in X) surgeon who does a lot of the procedures, or 
surgeons who have specialised training in, and restrict their practice to $\mathrm{X}$ - related surgery ( $\mathrm{X}$ being outpatient lumbar discectomy in our case).

Although no strong conclusions can be drawn due to the limitations of the study, we can conclude that lumbar microdiscectomy can be performed safely as an outpatient procedure by both spine and non-spine trained surgeons based on similar admission and acute complication rates. With exclusion of revision operations, the data suggests a trend favoring the SS group on both outcome measures which did not reach statistical significance likely due to the sample size in this study. This study also reemphasizes the importance of surgeons keeping highquality and complete prospective databases of their complications and outcomes.

\section{ACKnowledgments}

The authors thank Marina Englesakis for her help with the literature search.

\section{REFERENCES}

1. Chowdhury MM, Dagash H, Pierro A. A systematic review of the impact of volume of surgery and specialization on patient outcome. Br J Surg. 2007;94:145-61.

2. Hersht M, Massicotte EM, Bernstein M. Patient satisfaction with outpatient lumbar microdiscectomy: a qualitative study. Can J Surg. 2007;50:445-9.

3. Bookwalter JW, Busch MD, Nicely D. Ambulatory surgery is safe and effective in radicular disc disease. Spine. 1994;117:1738-45.

4. Korres DS, Loupassis G, Stamos K. Results of lumbar discectomy: a study using 15 different evaluation methods. Eur Spine J. 1992; $1: 20-4$.

5. Law JD, Lehman RAW, Kirsch WM. Reoperation after lumbar intervertebral disc surgery. J Neurosurg. 1978;48:259-63.
6. Osterman H, Sund R, Seitsalo S, Keskimaki I. Risk of multiple reoperations after lumbar discectomy: a population-based study. Spine. 2003;28:621-7.

7. Wiese M, Kramer J, Bernsmann K, Willburger RE. The related outcome and complication rate in primary microscopic disc surgery depending on the surgeon's experience: comparative studies. Spine J. 2004;4:550-6.

8. An HS, Simpson JM, Stein R. Outpatient laminotomy and discectomy. J Spinal Disord. 1999;12:192-6.

9. Asch HL, Lewis PJ, Moreland DB, Egnatchik JG, Yu YJ, Clabeaux $\mathrm{DE}$ et al. Prospective multiple outcomes study of outpatient lumbar microdiscectomy: should 75 to $80 \%$ success rates be the norm? J Neurosurg. 2002;96:34-44.

10. Singhal A, Bernstein M. Outpatient lumbar microdiscectomy: a prospective study in 122 patients. Can J Neurol Sci. 2002;29: 249-52.

11. Stolke D, Sollman WP, Seifert V. Intra- and postoperative complications in lumbar disc surgery. Spine. 1989;14:56-9.

12. Bednar DA. Analysis of factors affecting successful discharge in patients undergoing lumbar discectomy for sciatica performed on a day-surgical basis: a prospective study of sequential cohorts. J Spinal Disord. 1999;12:359-62.

13. Best NB, Sasso RC. Success and safety in outpatient microlumbar discectomy. J Spinal Disord Tech. 2006;19:334-7.

14. Shaikh S, Chung F, Imarengiaye C, Yung D, Bernstein M. Pain, nausea, vomiting and ocular complications delay discharge following ambulatory microdiscectomy. Can J Anesth. 2003;50: 514-8.

15. Woodrow SI, Bernstein M, Wallace MC. Safety of intracranial aneurysm surgery performed in a postgraduate training program: implications for training. J Neurosurg. 2005;102:616-21.

16. Reeves BC. Principles of research: limitations of non-randomized studies. Surgery (Oxford). 2006;24:263-7. 